\title{
Facing the Challenges of a Bilingual Education Program in the 21 st Century
}

\author{
Lucia Buttaro \\ Touro College, New York, USA
}

\begin{abstract}
Schooling involves more than reading, writing, and arithmetic. Schools also socialize students to embrace broader socio-cultural values and norms. Important socio-cultural values of public education in the Western world are appreciation and understanding of linguistic and cultural diversity as well as reduction of intolerance and prejudice towards others who are different from oneself. These are important goals for students in most schools, because they encounter linguistic and cultural differences in their own classrooms. As a result, getting to know and understand other languages and cultures is important for students to be able to empathize and appreciate many of their classmates

Keywords: bilingual education, oppression, English as a new language (ENL), limited English proficient (LEP), language minority students, linguistic growth, native language
\end{abstract}

\section{Facing the Challenges of Bilingual Education Classrooms in New York}

There are many advantages to being competent in two or more languages. It is these very advantages that provide the core motivation for bilingual education programs. Understanding these advantages is at the center of advocacy efforts on behalf of bilingual education both in communities that are planning to set up new programs and in communities that already have bilingual education programs. Being able to make a strong case for the advantages of bilingual education programs with cultural competence is particularly important in English dominant communities where it is often thought that knowing English is sufficient since it is a global language (Beeman \& Urow, 2012; Bigler, 1999; Cummins, 2007).

There are four arguments as follows (Freire, 1970, 1985, 1988; Valenzuela, 1999) that provide the educational value that support bilingual education:

1. To prevent the scholastic retardation which results from providing English-only instruction to children dysfunctional in English language skills, though they arrived at school with at least an array of conversational abilities in Spanish;

2. To stem the psychological oppression experienced by Spanish-speaking students in all-English classrooms;

3. To prevent the loss of Spanish-speaking students' potential and bilingual development;

4. To promote effective home-school collaboration.

\section{How to Prevent Scholastic Retardation}

Spanish-speaking children have experienced decades of English only instruction in public schools. The

Lucia Buttaro, Ph.D., Chair, Department of Bilingual Education/TESOL, Touro College. 
expectation was that these children would integrate successfully into the unilingual educational system. However, data showing "semi-lingualism" in several schools revealed differently (Beeman \& Urow, 2012). These students can have difficulty fitting into classrooms and benefitting from classroom experiences because teachers assume that they have the same funds of knowledge as mainstream students. This makes it difficult for English language learners (ELLs) to link new learning to prior experiences.

Participation in a bilingual program provides these students with experiences where different cultural norms and expectations are respected and practiced, and this in turn, broadens their cultural competence. This promotes positive intergroup attitudes and relations that can have a particularly positive impact on ELLs' self-esteem, and in turn, on their engagement in learning in school (Gonzalez, Moll, \& Amanti, 2005; Lantolf, 2005).

\section{Psychological Oppression}

The onset of the First World War in 1917 "fostered sentiments of nationalism and isolationism in the United States (U.S.) society, and existing concepts of cultural pluralism shifted toward the idea of cultural assimilation of all ethnic groups into a common mono-lingual, mono-cultural, English-speaking society" (Dorfman, 1998, p. 5), and these sentiments continued until the Civil Rights Movement of the 1960s. Minority ethno linguistic groups "were expected to learn English, forget their native language, and adopt the American way of life" (Dorfman, 1998, p. 5), particularly through English-only schooling.

Throughout the aforementioned period, Mexican American students were punished if they spoke Spanish in school. The "No Spanish Rule" was an educational policy that "emanated from the belief that Mexican American culture was inferior and damaging" (i.e., That it interfered with intellectual and emotional development) (Delpit, 1988, p. 107). This practice was adopted by many school systems in Texas, Colorado, New Mexico, Arizona, and California to discourage Mexican American students from speaking Spanish. A San Antonio Mexican American student gives a verbal account of the "No Spanish Rule" and its effect on his self-concept:

If they caught you talking Spanish, they would send you to the office and give you a warning. They would give you a long lecture about, if you wanted to be an American, you have got to speak English. And you were not a very good American ... I mean they are telling you that your language is bad. You hear it at home. Your mother and father speak a bad language, and you speak a bad language. (Erickson, 1990, pp. 189-190)

During the bilingual education hearings, expert witnesses commented "on the psychological damage which such practices rendered unto millions of children" (Fairclough, 1989, p. 1), especially Spanish-speaking children. It was argued bilingual education that would enable Spanish-speaking children to develop a positive self-concept via curriculum and pedagogy that validated their native language and culture while they internalized English and school culture, thus, benefiting from a culturally pluralistic learning environment. The National Education Association of the U.S. (1966) reported that "Spanish properly used could be a bridge to the learning of English instead of an obstacle and the Mexican American students could become truly bilingual and bicultural" (p. IV). This publication was "an important part of the Senate hearing record" (Fine, 1991, p. 2).

\section{How to Prevent the Loss of a Potential Bilingual Development}

Spanish-speaking children take their ethno-linguistic and socio-cultural heritage to school. School culture requires socialization and learning solely in English. Spanish-speaking students' success depends on their 
ability to learn English and process subject matter in English effectively. Doing so means that students are grade-level proficient in English. But Spanish-speaking students are not developing English literacy accordingly. The English-only approach in educating Spanish-speaking students is ineffective (Beeman \& Urow, 2012; Garcia, 2001). Bilingual education, many witnesses feel, would enable Spanish-speaking children to use the home language and culture to adapt positively to the culture of the school and learn content area material, thus developing literacy-related proficiency in the language they know best. Building a solid schooling foundation in the home language and through the use of culturally relevant instruction is seen as essential in developing classroom proficiency in English (Ogbu, 1987; Portes \& Rumbaut, 2006), hence, the pathway for potential bilingual development.

\section{How to Promote an Effective Home-School Collaboration}

Latino parents are affected by the all-English functioning school as well. While they are predominantly Spanish-speaking, matters associated with school events, including their children's school behavior, academic achievement or underachievement, and extracurricular activities are conducted solely in English. This dual communication dysfunction produces disconnectedness between the home and school. Thus, Spanish-speaking children are the avenues of contact and information sharing between both entities. A witness stated the following:

The only contact the school has with the parents is the children and the only contacts the parents have with the school are the children. But the child is neither bringing from home to share at school, nor does he take home to share with his parents. (Heath, 1983, p. 308)

The witness further added:

When the little ones go home and their mothers ask, "Qué aprendiste hoy (What did you learn today?)" The answer usually sounds like this, "Quién sabe! No le entiendo a la maestra (Who knows! I do not understand the teacher)," or if he has learned a few words, a few sentences in English, he will repeat them to his mother and she will answer, "Quién sabe que dirás! Yo no entiendo inglés, dime en español (Who knows what you are saying! I do not know English, tell me in Spanish.)" After a few days or weeks, she stops asking and he stops sharing ${ }^{1}$. (Heath, 1983, p. 308)

The above exemplifies the disconnectedness between the Spanish-speaking home and the English-only functioning school. Many witnesses argued bilingual education would establish effective collaboration between the home and school via teachers, counselors, administrators, and other school personnel proficient in English and Spanish bilingualism and biculturalism. Liaison between the school and the Spanish-speaking family is seen as another important component to students' success (Heath, 1983).

The Senate Labor and Public Welfare Committee's Special Subcommittee on Bilingual Education Hearings concluded on July 21, 1967. After much congressional deliberation, President Lyndon B. Johnson signed into law the Bilingual Education Act on January 2, 1968, "making bilingual education a federal policy for the first time in the history of the U.S." (Kohl, 1994, p. 29). While Senate Bill 428 was originally intended for Spanish-speaking students, especially students of Mexican American descent, the Bilingual Education Act "adopted the broader approach" (San Miguel, 2001, p. 17) and authorized the utilization of federal monies for the education of non-English speaking students (Shor, 1992).

\footnotetext{
${ }^{1}$ In Spanish, questions have an interrogation mark upside down in front of the question and a regular one in the back, also, exclamation marks are double as well, one is upside down in front and the other in regular format in the back.
} 


\section{Effective Programs in Bilingual Education}

The long road of creating equitable opportunities for English language learners continues to this day in most parts of the country and in order to better serve the English language learner population in New York. The study started in September of 2015. The principal investigator for the study was the "education specialist" who was working for a university located in New York City at the time. The purpose of the study was to profile the programs, policies, and instructional practices of successful schools for limited English proficient (LEP) students. Six school sites were visited. These schools also had over an $80 \%$ LEP population. The six schools selected for the study were School A in the Bronx, School B in the Bronx, School C in Manhattan, School D in Charter Middle School in the Bronx, School E in Middle School in the Bronx, and School F in Queens.

This study was to examine the significant features of successful programs for LEP students. Four of the six schools are considered "renewal" schools and one of them is also in "receivership" which means that the scores need to increase in order to avoid being taken over by the State of New York.

The researcher decided to examine data over a two year period. In all cases, the schools either sustained the same accountability rating, or improved.

\section{Research Design and Methodology}

In researching the characteristics of these six schools, the methodology used in this study is of a descriptive nature. Descriptive research is used in the literal sense of describing situations or events. It is the accumulation of a data base that is solely descriptive, and it does not necessarily seek or explain relationships, test hypothesis, make predictions, or get at meanings and implications, although research aimed at these more powerful purposes may incorporate descriptive methods (C. Suarez-Orozco \& M. Suarez-Orozco, 2001).

The methodology is an operational framework within which the data collected are placed, so that their meaning may be seen more clearly. Two major approaches are used for collecting and analyzing data: quantitative and qualitative. This study uses both the qualitative and quantitative approach. The qualitative approach is typically used to answer questions about the nature of the phenomena with the purpose of describing and understanding the phenomena from the participant's point of view (Stein, 1971). Qualitative researchers regard their research task as "coming to understand and interpret how the various participants in a social setting construct the world around them" (Trueba, 1989, p. 6). Although qualitative research may not explicitly address the issue of generalizability, the concept of transferability is similar (Stein, 1971).

Quantitative research seeks to explain and make predictions that will generalize to other persons and places. The intent is to establish, conform, or validate relationships and to develop generalizations that contribute to theory. Quantitative research has been used in some parts of the study. The research questions addressed were:

1. What are the district leadership practices that facilitate academic and linguistic growth/success for language minority students?

2. What are the campus leadership practices that facilitate academic and linguistic growth/success for language minority students?

3. What are the characteristics of the teaching staff that facilitate academic and linguistic growth/success for language minority students? 
4. What are effective teaching practices that facilitate academic and linguistic growth/success for language minority students?

5. What are the characteristics of parents and parental involvement on the six campuses?

6. What are the characteristics of program(s) serving language minority students?

\section{Data Collection}

The study data gathering included a teacher questionnaire and interviews, interview with the district administrator responsible for the district bilingual education program, campus administrator questionnaire and interviews, parent interviews, and on-site school classroom visitations by the investigator. The questionnaire included multiple choices, Yes/No, open-ended, and Likert type questions. The teacher questionnaires were subsequently given to all six schools for distribution to the bilingual teachers that taught at the school during the years designated to the study. Teacher questionnaires were filled out before hand and brought to the on-site interviews. Principal questionnaires were filled out during the on site interviews.

The on site visits consisted of weekly, or biweekly visits to the six schools during the years 2015-2016 and 2016-2017. During the school visits, the investigator had interviews with the district administrator (bilingual coordinator/director), the campus principal, teachers, and parents. Classroom visits were conducted at each school site to observe the bilingual classroom for effective bilingual education classroom practices that were consistent with the current research. The investigator visited and observed in each classroom for about 30-45 minutes. Non-bilingual education classrooms were also observed to see what effective teaching practices were also present throughout the school. The investigator noted anecdotal records and took notes during observations in the classrooms.

Collected data were then analyzed. Triangulation, used in all types of qualitative research, is the process of using multiple data collection methods, data sources, analysts, or theories to check the validity of the findings. If similar themes are noted in data collection from the different sources, the credibility of the interpretations is enhanced. The data was collected from the district level perspective, the campus administration, teacher, and the parent in an attempt to validate the findings of the study.

\section{Analysis of the Data}

The study findings supported the research questions. The research findings of the data were divided according to the data collection procedures used, specifically teacher questionnaire responses, teacher interviews, campus administrator interviews, district bilingual director interviews, and parent interviews.

\section{District Leadership}

There are several district leadership practices that facilitate academic and linguistic growth/success for language minority students in this district. In their recent study on effective practices for improved student performance, the New York City Department of Education has requested that the schools follow a specific format for bilingual education programs (as per the Chancellor Ms. Carmen Fariña and the Deputy Chancellor, Ms. Milady Baez). District support for teacher and administration professional training includes regular training practices. According to Baker (1998, p. 77):

The call for teachers as public and critically engaged intellectuals and cultural workers places teacher work at the forefront of pedagogical politics that raises questions, subjectivist knowledge with which they labor, and pushes classrooms toward a democratizing notion concerning schooling. 


\section{Campus Leadership}

Four principals of the schools had extensive training in bilingual and English as a new language (ENL) education with a Master's Degree in bilingual education. They had also been a bilingual or an ENL teacher, thus, having knowledge of bilingual education philosophy and theory.

Certification can prove to be essential in the process of a program ... Several organizations have developed guidelines and certification standards for teachers who work in ENL and bilingual programs. These standards build on basic program standards and also include proficiency in written and oral forms of two languages, as well as skills in developing students' language abilities. (Corson, 1993; Cummins, 2007)

One principal was an instructional leader monitoring and visiting classrooms frequently during the week, focusing the teachers on instruction through vertical and horizontal planning on a weekly basis, and empowering teachers to make instructional decisions in their classrooms. Teachers expressed that they felt that the principal was collaborative in their leadership with high expectations of the staff and the students. Such practices are reflected in the professional literature:

Specific characteristics crucial to the development of effectiveness and thus to a positive school social climate in bilingual schools include: a safe and orderly school environment, common agreement on a strong academic orientation with clearly stated academic goals, objectives, and plans, well organized classrooms, and well functioning methods to monitor school inputs and students' outputs. (Portes \& Rumbaut, 2006)

One of the foci of the principals was in providing staff development to the teachers in the area of literacy development on a yearly basis. Updating teacher knowledge makes the difference for students daily through dynamic learning. The principals also keep informed on student test scores through open communication with their faculty. An awareness of the quality of testing can make a difference. The principals are also aware of the strengths and weaknesses of the staff through daily classroom visits. The principals are very familiar with the community, and the parents commented that they felt welcomed at the school. In addition, the social climate is often determined by the principals and their attitude toward the community, a well functioning total system producing a school social climate that promotes positive student outcomes is one characteristic of an effective bilingual school (Nieto, 1999, 2000, 2003; Portes \& Rumbaut, 2006).

Altogether, the characteristics of the principals lay the groundwork for success in the total school program:

The following attributes are identified as being associated with effective schools and classrooms: a supportive school-wide climate, school leadership, a customized learning environment, articulation and coordination within and between schools, some use of the native language and culture in the instruction of language minority students, a balanced curriculum that incorporates both basic and higher order skills, explicit skills instruction opportunities for student-directed activities, use of instructional strategies that enhance understanding, opportunities for practice, systematic student assessment, staff development, and home and parent involvement. (Corson, 1993; Cummins, 2007)

\section{Teaching Staff}

Some of the teachers on the school campuses are bilingual or ENL certified, which is essential to long-term success in the program (Dorfman, 1998). Most of the staff taught at the school for more than 10 years (except for the Charter School since they are relatively new) and they attribute this longevity and stability as contributing to the success of the students. There are teachers from The Dominican Republic, Honduras, Guatemala, El Salvador, Cuba, and Peru on the staffs of some of the schools that know the finite points of the Spanish language and are able to teach the Spanish Language Arts with a high degree of proficiency. 
Teachers believe all students can learn and have high expectations. They described themselves as caring, but structured in their approach to the delivery of the curriculum. Second language learners' success is often predetermined by teacher expectation (Erickson, 1990).

In most schools, teachers meet on a weekly basis for either vertical or grade level planning. During the planning, the teachers develop six weeks' plans to address the needs of the students. Ensuring internal support through regular planning periods creates a successful school climate in the school, research indicates that the successful:

Climate includes the following components: high staff expectations for children and the program, strong demand for academic performance, high staff morale. High staff morale includes the following: strong internal support, consensus building, job satisfaction, sense of personal efficacy, sense that the system works, sense of ownership, well defined roles and responsibilities, belief and practice that resources are best expended on people rather than on educational soft and hardware. (Valenzuela, 1999)

The development of teacher made materials and teacher designed thematic units enrich the curriculum. They are also able to discuss the progress of students during the planning meetings, and thus, able to closely monitor the progress of each student through open communication. Teachers have a limited use of dittos, and they focus on direct, large group instruction, small group activities, and cooperative learning.

\section{Teaching Practices}

There are many practices that facilitate the academic and linguistic growth/success for language minority students. The use of both Spanish and English for direct instruction was evident in all classrooms. This is necessary for success with second language learners and does not impede progress in English (San Miguel, 2001). Instruction delivered in the primary language can have a profound effect on the development of academic English. Firstly, the primary language can be used to teach subject matter. If children know subject matter, they will understand much more of what goes on in the classroom in English, resulting in more acquiring of language as well as knowledge. Secondly, the primary language can be used to develop literacy, which transfers to the second language. There is strong evidence that programs that utilize the first language in this manner are effective in promoting academic English language development (Baker \& Jones, 1998). Anyon (1981) and Garcia (2001) addressed the extensive comparative literature on instructional practices that contribute to the literacy development of bilingual populations. Almost all of these studies included Latino students (Donato, 1997). The investigator used meta-analysis to combine academic achievement scores from a large set of statistically unrelated studies. This meta-analysis indicated that bilingual education programs significantly enhanced academic achievement, in comparison to English instructional programs. Dorfman (1998) conducted a more traditional review of related independent studies and they reached the same conclusions. Teachers acknowledge equal prestige to both the English and Spanish languages during instruction, and when eliciting student responses, an essential characteristic of success (Garcia, 2001; Trueba, 1989). Most recently the National Literacy Panel on Language Minority Children and Youth (Shor, 1992) concluded that in summary, there is no indication that bilingual education impedes academic achievement in either the native language or English. The classroom environment is rich in both English and Spanish materials. Suarez-Orozco (2001) noted that children who made greater use of books in the first language provided by the school had a greater feeling of security in their cultural background. Teacher made materials in both English and Spanish were also readily available in the student centers, one of the components of successful bilingual programs (Valenzuela, 1999). 


\section{Learning to Foster Native Language Literacy}

The responsibility to create excellent learning environments for language minority students should not rest with individual teachers alone. Entire schools can develop such environments. Suarez-Orozco (2001) analyzed eight exemplary school reform efforts for language minority students and found that all of the schools shared the following common characteristics, among others:

1. They had a school wide vision of excellence that incorporated students of limited English proficiency;

2. They created a community of learners engaged in active discovery;

3. They created programs to develop both the English and native-language skills of language minority students;

4. They made a conscious effort to recruit and hire bilingual staff members;

5. They honored the multi-cultural quality of the student population.

Bilingual programs also have secondary salutary effects, such as motivating students to remain in school rather than dropping out, making school more meaningful, and in general making the school experience more enjoyable. A related phenomenon is that bilingual education may reinforce close relationships among children and their family members, promoting more communication than would be the case if they were instructed solely in English and lost their native language. This is what the researcher found through interviews with immigrant parents when their preschool children were placed in English only settings. Not only did the children lose their first language, but more significantly, they lost the ability to communicate with their parents and families. In the process, they also lost the academic advantage that fluency and literacy in a language would give them when they begin school.

In Nieto's (2000) research with academically successful students, she found that maintaining language and culture were essential in supporting and sustaining academic achievement. In a series of in depth interviews with linguistically and culturally diverse students, one of the salient features that accounted for school success was a strong willed determination to hold on to their culture and language. Although their pride in culture and language was not without conflict, the steadfastness with which they maintained their culture and language in spite of widespread negative messages about them was surprising.

\section{Conclusions}

Language is one of the fundamental signs of our humanity. It is the palette from which people color their lives and culture (Allman, 1990). Although linguistic diversity is a fact of life in American schools and society, many languages are not accorded the respect and visibility they deserve. But given recent trends in immigration, the shrinking of our world, and the subsequent necessity to learn to communicate with larger numbers of people, a reconceptualization of the roles of languages other than English in our schools and society is in order. Given this kind of reconceptualization, current school policies and practices need to be reexamined. Those that build on students' diversity need to be strengthened, while those that focus on differences and deficits must be eliminated. This means, at the very least, that bilingual and multi-cultural programs for all students have to be comprehensively defined, adequately funded, and strongly supported.

The issue of what to do about language minority students goes much deeper than simple language diversity. Above all, it is an issue of educational equity. Whether bilingual education, ENL, or other approaches and support services are offered, they need to be developed with an eye toward promoting, rather than limiting, educational opportunities for all students. Given the increasing number of students who enter schools speaking 
a language other than English, it is clear that attending to the unique condition of language minority students is the responsibility of all educators. For students with limited English proficiency, suitable approaches geared to their particular situation are not frills, but basic education. For English mono-lingual students, too, learning to appreciate and communicate in other languages is a gift to be cherished. When we approach language diversity as a resource that is respected and fostered, all students benefit.

\section{References}

Allman, W. F. (1990, November 5). The mother tongue. U.S. News and World Report, 60-70.

Anyon, J. (1981). Social class and school knowledge. Curriculum Inquiry, 11(1), 3-41.

Baker, C., \& Jones, S. P. (1998). Encyclopedia of bilingualism and bilingual education. Clevedon, England: Multilingual Matters.

Beeman, K., \& Urow, C. (2012). Teaching for biliteracy: Strengthening bridges between languages. Philadelphia: Caslon.

Bigler, E. (1999). American conversations: Puerto Ricans, White ethnics, and multicultural education. Philadelphia: Temple University Press.

Corson, D. (1993). Language, minority education and gender: Linking social justice and power. Clevedon, UK: Multilingual Matters.

Cummins, J. (2007). Language, power and pedagogy: Bilingual children in the crossfire. Clevedon, England: Multilingual Matters.

Delpit, L. (1988). The silenced dialogue: Power and pedagogy in educating other people's children. Harvard Educational Review, 58(3), 280-298.

Donato, R. (1997). The other struggle for equal schools: Mexican Americans during the civil rights movement. Albany: State University of New York Press.

Dorfman, A. (1998). Heading south, looking north: A bilingual journey. New York, NY: Penguin.

Erickson, F. (1990). Culture, politics, and educational practice. Educational Foundations, 4(2), 21-45.

Fairclough, N. (1989). Language and power. New York, NY: Longman.

Fine, M. (1991). Framing dropouts: Notes on the politics of an urban high school. Albany, NY: SUNY.

Freire, P. (1970). Pedagogy of the oppressed. New York, NY: Seabury.

Freire, P. (1985). The politics of education: Culture, power, and liberation. New York, NY: Bergin \& Garvey.

Freire, P. (1998). Teachers as cultural workers: Letters to those who dare to teach. Boulder, CO: Westview.

Garcia, E. E. (2001). Hispanic education in the United States: Raices y alas. New York, NY: Rowman \& Littlefield.

Gonzalez, N., Moll, L. C., \& Amanti, C. (2005). Funds of knowledge: Theorizing practices in households, communities and classrooms. Mahwah, NJ: Lawrence Erlbaum.

Heath, S. B. (1983). Ways with words. New York, NY: Cambridge University Press.

Kohl, H. (1994). "I won't learn from you” and other thoughts on creative maladjustment. New York, NY: The New York Press.

Lantolf, J. P. (2005). Socio-cultural theory and L2 learning: An exegesis. In E. Hinkel. (Ed.), Handbook of second language research (pp. 335-354). Mahwah, NJ: Erlbaum.

Nieto, S. (1999). The light in their eyes: Creating multicultural learning communities. New York, NY: Teachers College Press.

Nieto, S. (2000). Affirming diversity: The sociopolitical context of multicultural education (3rd ed.). New York, NY: Longman.

Nieto, S. (2003). What keeps teachers going? New York, NY: Teachers College Press.

Ogbu, J. U. (1987). Variability in minority school performance: A problem in search of an explanation. Anthropology and Education Quarterly, 18(4), 312-334.

Portes, A., \& Rumbaut, R. G. (2006). Immigrant America: A portrait (3rd ed.). Berkeley: University of California Press.

San Miguel, G., Jr. (2001). Brown, not white: School integration and the Chicano movement in Houston. College Station: Texas A \& M University Press.

Shor, I. (1992). Empowering education: Critical teaching for social change. Chicago: University of Chicago.

Stein, A. (1971). Strategies for failure. Harvard Educational Review, 41, 133-179.

Suarez-Orozco, C., \& Suarez-Orozco, M. (2001). Children of immigration. Cambridge, MA: Harvard University Press.

Trueba, H. T. (1989). Raising silent voices: Educating the linguistic minorities for the 21st century. Cambridge, MA: Newbury House.

Valenzuela, A. (1999). Subtractive schooling: U.S.-Mexican youth and the politics of caring. New York, NY: State University of New York Press. 